\title{
Synthesis and Structural Study of Ferroelectric Material Lead Titanate ( $\left.\mathrm{PbTiO}_{3}\right)$
}

\author{
Avantika Chauhan $^{1 *} \cdot$ Srishti Paliwal $^{2} \cdot$ S.C Bhatt ${ }^{3}$ \\ ${ }^{1}$ Department of Physics, Devbhoomi group of institutions, Chakrata Road Navgaon, Manduwala, Dehradun- \\ 248007, Uttarakhand, India. \\ ${ }^{2}$ School of material science and technology, Indian institute of technology BHU, Varanasi (221005), Uttar Pradesh, \\ India. \\ ${ }^{3}$ Department of Physics, HNB Garhwal University, Srinagar, Uttarakhand.
}

*Corresponding Author E-mail id: chauhanavni1997@gmail.com

Received: 2.8.2021; Revised: 16.9.2021; Accepted: 29.9.2021

(C) Society for Himalayan Action Research and Development

\begin{abstract}
Lead Titanate $\mathrm{PbTiO}_{3}$, (PT) is technologically important ferroelectric and piezoelectric ceramics. To make $\mathrm{PbTiO}_{3}$, the oxides $\mathrm{PbO}$ and $\mathrm{TiO}_{2}$ are combined in a stoichiometric ratio. Solid-state reaction process was used to synthesize the oxides. The calcination temperature was $850^{\circ} \mathrm{C}$. The prepared sample has been characterized by XRD techniques with a scanning rate of 6 degree per minutes. The prepared sample $\mathrm{PbTiO}_{3}$ shows crystalline nature, with Tetragonal symmetry, as observed by X -ray measurements. A scanning electron microscope (SEM) was used to examine the surface morphology and grain size of the obtained samples. Micrographs obtained from SEM analysis revealed a single phase sample of well-defined grains.
\end{abstract}

Keywords: Solid state reaction, XRD, SEM, Ferroelectric, Piezoelectric.

\section{Introduction}

Lead titanate $\mathrm{PbTiO}_{3}$ is a perovskite crystal having a general formula $\mathrm{ABO} 3$. It is a ferroelectric material, sustain a static electric field into it with remarkable piezoelectric and pyroelectric properties. It has relatively large rate of electromechanical transduction and pyroelectric coefficient (Pillai, C. S., \& Ravindran, P.V. 1996), due to which it becomes an excellent material having enormous number of necessitating applications, such as in switches, motor starters and controllers, sensors, multilayer capacitors, gas igniters and many more. Recently to synthesize the nanometer sized lead titanate particles, from mixed oxides at room temperature, mechanical activation method has been widely used. $\mathrm{PbTiO}_{3}$ stoichiometry is considered to be an effective factor in maintaining better electro thermal (Rai, R., Mishra et.al. 2011) properties. In general, the process for making it involves heating $\mathrm{PbO}$ and $\mathrm{TiO}_{2}$ to temperatures more than $1275{ }^{\circ} \mathrm{C}$, which is considerably higher than the melting point (m.p.) of $\mathrm{PbO}$ and typically results in $\mathrm{Pb}$ deficient $\mathrm{PbTiO}_{3}$ (Bongane and Gavli 2020). Sol-gel rout method and many more chemical processing techniques, are the different preparative methods, which are used to minimize lead loss and this allows stoichiometric lead titanate to be obtained and its stable oxide solutions. And if both techniques are more complicated and involved than the solid-state process, they have the objective of reducing the compound processing temperature. Our findings demonstrate unequivocally that the lead titanate $\left(\mathrm{PbTiO}_{3}\right)$ can be generated at lower temperatures than previously reported (Bongane and Gavli 2020) using a conventional solid state system. The compound forming reaction begins at approximately $800{ }^{0} \mathrm{C}$, where the vapour pressure of the $\mathrm{PbO}$ oxide is negligible. Because 
of lead degradation, the titanate of lead processed at or above the $850{ }^{\circ} \mathrm{C}$ is less susceptible to non- stoichiometry (Sati et.al. 2020). SEM and XRD techniques were used to characterise the low temperature generated lead titanate samples.

\section{Methods}

The lead titanate was made using the reaction process in the solid-state, which is one of the finest for preparing samples. $\mathrm{PbO}$ and $\mathrm{TiO}_{2}$ (rutile) powders were combined and blended entirely and stoichiometrically at the right time. For the preparation $\mathrm{PbTiO}_{3}$ the constituents $\left(\mathrm{PbO}, \mathrm{TiO}_{2}\right)$ are weighted in an electronic digital balance and we grind the raw material for 90 minutes after mixing it. Using agate mortar before allowing it to dry thoroughly. After that, the ground mixture was calcined for four hours in an alumina crucible at $850{ }^{\circ} \mathrm{C}$. Calcinations aid in the removal of both toxic and gaseous materials from the powder. The powder was ground and processed after the calcinations. The formulation of the product and the completion of the reaction were determined using an X-ray diffractometer (XRD) using (PANanalytical, X'PERT PRO) diffractometer employing $\mathrm{CuK}_{\alpha}$ radiation with a wavelength of $1.5405979 \AA$, for the broad range of $2 \theta\left(20^{\circ}<2 \theta\right.$ $<80^{\circ}$ ) at a scanning rate of 6 degree/ minute. A scanning electron microscope (CARL ZEISS, MA15/EVO18) (Singh, S., et.al. 2018) was used to investigate the grain size and surface morphology of the prepared sample.

\section{Result and Discussion X-Ray Differaction Results}

X-ray diffraction patterns of $\mathrm{PbTiO}_{3}$ were recorded using (Rai, R. 2005) X-ray diffractometer using (PANanalytical, X'PERT PRO) diffractometer employing $\mathrm{CuK}_{\alpha}$ radiation having wavelength $1.5405979 \AA$. Sharper $\mathrm{PbTiO}_{3}$ diffraction peaks with hkl (001) (100) (101) (110) (111) (002) (200) etc. values, these planes indicate that the samples are more homogeneous and crystallized. $\mathrm{PbTiO}_{3}$ has a single phase with a tetragonal configuration, according to the x-ray analysis. With the ICSD data of $\mathrm{PbTiO}_{3}$ (Card no. 01-070-7729), all reflections were indexed by hkl value and using the hkl we calculate the interplaner spacing ' $d$ ' for these planes, and grid parameters were determined using the least square method of refining.. A strong match between measured and observed values for all $\mathrm{PbTiO}_{3}$ diffraction lines which indicates that the prepared sample is a perovskite ferroelectric substance that can be used as an electro optic waveguide (assuming no changes in the basic crystal structure).

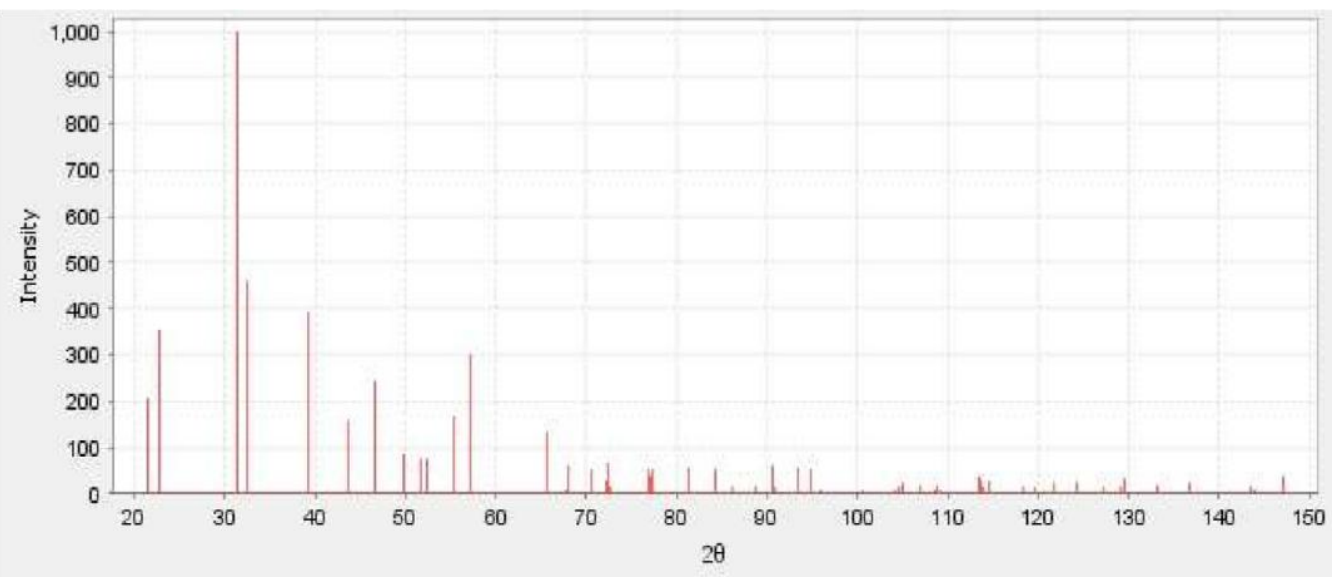

Figure 1. XRD pattern of $\mathrm{PbTiO}_{3}$ from ICSD (No. 01-070-7729) 


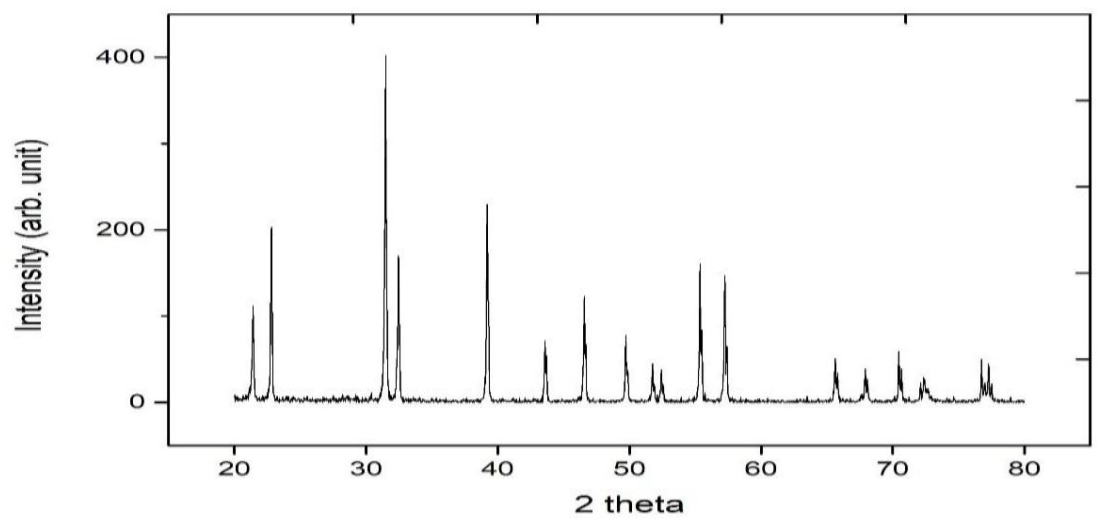

Figure 2. XRD pattern of $\mathrm{PbTiO}_{3}$

The data of $\mathrm{PbTiO}_{3}$ and XRD from the ICSD card are seen in fig. 1. (No.: Card no. 01-0707729). The observed details of $\mathrm{PbTiO}_{3}$ and XRD are seen in graph 2. High amplitude reflection peaks of

$2 \theta=21.4190(001)$ plane, $2 \theta=22.3150(100)$ plane,

$2 \theta=31.4870$ (101) plane, $2 \theta=32.4730$ (110) plane,

$2 \theta=39.2230(111)$ plane, $2 \theta=43.6140(002)$ plane,

$2 \theta=46.5700(200)$ plane, $2 \theta=49.7690(102)$ plane,

$2 \theta=51.7320(201)$ plane, $2 \theta=52.4470(210)$ plane,

$2 \theta=55.3910(112)$ plane, $2 \theta=57.2750(211)$ plane,

The data points of $2 \theta$ and $\mathrm{d}$ are almost identical to the ICSD values. The highest reflection spike can be found at $2=31.4870$ (101) plane, which corresponds to $2 \theta=31.47860$ in ICSD (101). The' $d$ ' spacing were calculated by using Braggs law, where $\lambda=1.5405979 \AA$. $a=3.900 \AA$, $\mathrm{b}=3.900 \AA$, and $\mathrm{c}=4.150 \AA$ are the lattice parameters with $\mathrm{c} / \mathrm{a}=1.064, \mathrm{a} / \mathrm{b}=1.00$, and $\mathrm{c} / \mathrm{b}$ $=1.064$. The cell volume of $\mathrm{PbTiO}_{3}$ is $63.12 \AA$ and the crystal symmetry is noncentrosymmetric.

\section{SEM Result}

A CARL ZEISS MA15/EVO18 (Singh, S., et.al. 2018) scanning electron microscope (SEM) was used to capture the scanning electron micrographs at room temperature. The above figures depict a standard SEM micrograph of $\mathrm{PbTiO}_{3}$.

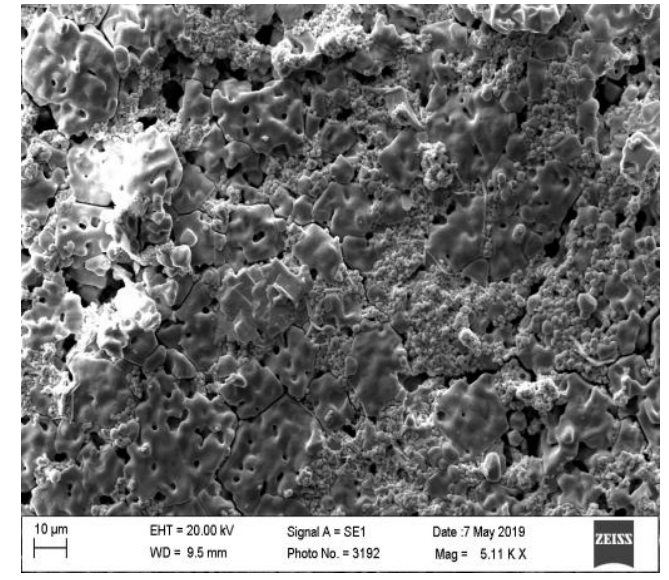

Figure 3. SEM micrograph of $\mathrm{PbTiO}_{3}$

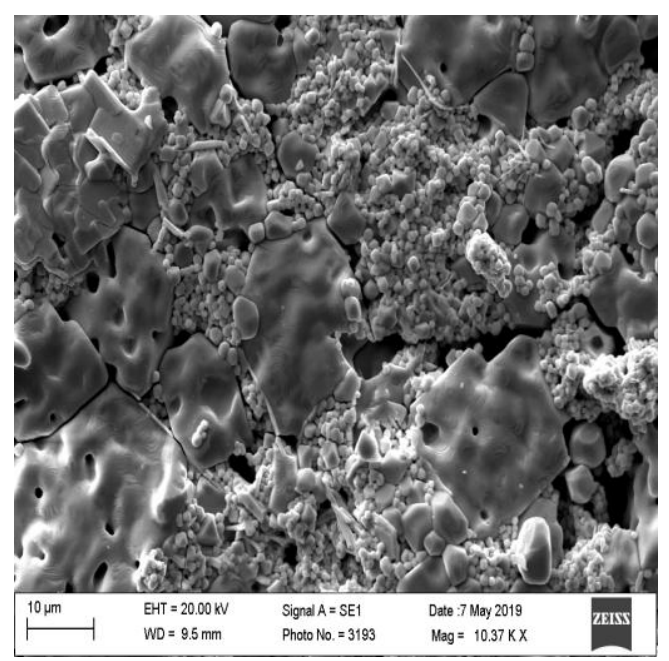

Figure 4. $\mathrm{SEM}$ micrograph of $\mathrm{PbTiO}_{3}$

The grains are measured in micrometers and the samples are regular. The grain size of 10 $\mu \mathrm{m}$ seems in a single phase. 


\section{Conclusion}

Heat treatment of $\mathrm{PbO}$ and $\mathrm{TiO}_{2}$ mixtures at $850^{\circ} \mathrm{C}$ was used to yield the compound. An Xray diffraction pattern with a well-defined pattern demonstrated the high efficiency of crystal forming. The XRD of lead titanate has been verified to be virtually identical to the ICSD norm (No. 01-070-7729). The lead Titanate sample has $\mathrm{ABO}_{3}$ perovskite, according to ICSD. The findings demonstrate experimentally that $\mathrm{PbTiO}_{3}$ can be produced by the reaction of solid-state mechanism having a stoichiometric mixture of $\mathrm{PbO}$ and $\mathrm{TiO}_{2}$ at 850 ${ }^{0} \mathrm{C}$. Lead Titanate material has a tetragonal crystal symmetry.

\section{References:}

B. K. Bongane and P. G. Gawali. (2020) "Synthesis, and Electronic Application of $\mathrm{PbTiO}_{3}$ at $\mathrm{GHz}$ Frequency", Communicated to the International Journal of Science and Research, ISSN (Online), www.ijsr.net.

Pillai, C. S., and Ravindran, P. V. (1996). Studies on the formation of lead titanate by solid state reaction from $\mathrm{PbO}$ and TiO2. Thermochimica acta, 278, 109-118.

Rai, R., Mishra, S. K., Singh, N. K., Sharma, S., and Kholkin, A. L. (2011). Preparation, structures, and multiferroic properties of single-phase $\mathrm{BiRFeO} 3, \mathrm{R}=\mathrm{La}$ and $\mathrm{Er}$ ceramics. Current Applied Physics, 11(3), 508-512.

Sati, S. C., Kour, G., Bartwal, A. S., and Sati, M. D. (2020). Biosynthesis of Metal Nanoparticles from Leaves of Ficus palmata and Evaluation of Their Antiinflammatory and Anti-diabetic Activities. Biochemistry, 59(33), 3019 3025.

Singh, S., Negi, J., and Panwar, N. S. (2018). Dielectric properties of $\mathrm{Na} 1-\mathrm{xKxNbO3}$, near $\mathrm{x}=0.5$ morphotropic phase region. Journal of Physics and Chemistry of Solids, Applied Innovative Research; 2: 311-317. 